\title{
The red dirt stays in your shoes: Reflective practice and both-ways learning
}

\author{
Sue Erica Smith \\ Charles Darwin University \\ sue.smith@cdu.edu.au
}

Keywords: Indigenous; teacher education; reflective practice; narrative

\begin{abstract}
This paper tracks the pedagogical genealogy that informs the delivery of the Growing Our Own program: longstanding and continuous commitment to Indigenous education from the Catholic sector, navigations to include bilingual education, and the articulation of both-ways learning and red dirt pedagogy. This mapping is interspersed with some poetic signposts, from an undergraduate participant and the author, as artefacts that illustrate enactment and embodiment this approach to teacher education: how the undergraduate participants can be empowered by the program, and how teaching in the program demands reflective, reflexive and perhaps transformative practices by the lecturers.
\end{abstract}

\section{Introduction}

The footprints of educators and teacher educators cross the breadth of the Northern Territory (NT). These have shaped the development and delivery of the Growing Our Own (GOO) program and continue to leave signposts in the Indigenous education landscape nationwide. The GOO program is delivered in partnership by the Catholic Education Office and the College of Education at Charles Darwin University (CDU). It has grown from the forerunner educators and institutions in the NT: the Northern Territory Department of Education; Batchelor College, now the Batchelor Institute of Indigenous Tertiary Education (BIITE); and Darwin Community College's evolution into the Darwin Institute of Technology, then the Northern Territory University, and now Charles Darwin University.

The GOO program operates in a selection of Catholic schools under the remit of the Catholic Education Office NT. It is, in many respects, an evolution of the sustained Catholic commitment to Aboriginal education in remote and very remote communities since the 1800s. It is fitting that the first NT mission school began in Daly River in 1886 (O'Loughlin, 1986) and is today producing graduate teachers from the GOO program.

The program draws its heritage from 1950, when the Commonwealth Government assumed responsibility for remote Aboriginal education and, with bipartisan agreement, deemed that bilingual education was desirable. This marked an important signpost for the direction of Aboriginal education because Aboriginal students in remote and very remote areas are bilingual or multilingual. That reality needed to be accommodated if their success in education was to be assured. A genealogy of how this significant challenge has been met, or not, has been tracked by Nicholls (2005), and more extensively in mappings of bilingual education in the NT by Devlin, Disbray and Devlin (2017). Qualified Aboriginal teachers were needed, and are still needed, and this challenge continues to inform the delivery of programs such as GOO. Connection to land, home, family and culture in which language is integral, hallmark indigenous identity and the program seeks to fulfil these aspirations by delivering Initial Teacher Education (ITE) degrees on-country. Bilingual education remains a perennial challenge faced by educators, policy makers and communities who strive for equitable education outcomes for Indigenous Australians and finding ways to utilise the various language assets of the students within a mainstream education degree continues to both enrich and at times challenge us all. 
The quest for equity in education and teacher education in Indigenous contexts has also been mapped by Guenther, Bat and Osborne (2014) whose scholarship into democratic, compassionate and equitable pedagogies they called red dirt thinking. This work was occurring contemporaneously with the GOO program, and, sharing such a philosophy and requiring culturally responsive and practical pedagogy (Guenther, Disbray and Osborne, 2015) their red dirt approach continues to resonate with me. Guenther, Disbray, \& Osborne (2015) have sought alternative indicators of 'success' to match the aspirations of local people living in remote communities. In this paper I extend the metaphor to reflect on my own experience, and potential indicators of the teacher herself.

\section{A lecturer on-country}

Academic staff arrive in remote communities equipped with skills, knowledge and student-centred pedagogies but, invariably, with scant knowledge of the languages and cultures of our students. My uncertainties were keenly felt, and I wrote:

I pick up the 4XD twin cab at 6:00 and am on the highway by 6:30 a.m. getting some distance before the rising sun reaches cabin height. The Bureau of Meteorology site says that the road in is still closed, but the school has confirmed that it is open. I hope there will be no more rain. I pass a few road trains and reach the first turn-off, and l'm into the windy stretch past hills and termite mounds, hoping that no wallabies spring out onto the road. A few hours on and I reach the community. It's their first subject in the course, Academic Literacies. We are a couple of weeks into it, and each time I go down there, I rack my brains to find points of engagement, relevance, or even faint enjoyment. In this remote classroom, the conventions of the academy are sifted, summarised, redrafted and crafted (there will be no plagiarism here) and referenced (meticulously). It is so white, so prescriptive, so alien. I am white, prescriptive, an alien.

The elders sit outside under a tree. They are keeping an eye on the students, and me. It is important that we all get through. (Smith, 2017, p.54-5)

As Lowell and Devlin (1999) found, even with good resources, careful preparations, scaffolding the learning and with the best of intentions, miscommunications between Aboriginal students and their non-Aboriginal teachers will be inevitable. It was incumbent on me, the academic, to work to mitigate these barriers if academic progress was to be made. Learning could only occur in mutuality with the teacher learning from the students, and for the students to be learning from the teacher. This pedagogical reciprocity is now known nationally as both-ways learning.

\section{Both-ways learning}

Both-ways education is about allowing the students to have the freedom to be who they are, yet at the same time empowering them with essential knowledge, skills and concepts from the western domain to enable them to make key decisions in their lives, be they professional or personal. (Ober, 2004, p.9)

A both-ways teaching philosophy, as elucidated by Ober and Bat (2007), enabled both Indigenous and western knowledges and ways of learning on campus, on-country or in workplaces. Batchelor Institute of Indigenous Tertiary Education that had been providing tertiary and further education to Aboriginal Teaching Assistants since the 1960s had embedded this culturally responsive, both-ways pedagogy throughout their courses. Educators at CDU were inspired by the potential afforded by this approach and drafted a submission to the Federal Government for a program that would join culturally relevant knowledge, and ways of being and doing, with contemporary curriculum and pedagogy (Elliott and Keenan, 2008). This was the genesis of Growing Our Own. 


\section{The cultural interface}

From the outset, the GOO program presented a bold innovation in higher education teaching. Founding educators, Slee and Keenan (2009), a former CDU colleague and a Catholic Education Office Deputy Director respectively, recognised that the requisite intersection between higher education and Indigenous experience in the GOO program was complex and required flexibility at all levels of the system for it to work. Teaching and learning occurred at cultural interfaces, constituted by points of intersecting trajectories that would take detours, sometimes stall, and forge new paths. Teaching and learning Growing Our Own is always a multi-layered and multi-dimensional space. Nakata (2007) describes the space: one of dynamic relations constituted by the intersections of time, place, distance, different systems of thought, competing and contesting discourse within and between different knowledge traditions, and different systems of social, economic and political organisation.

GOO students are Aboriginal Teaching Assistants seeking to become qualified as registered teachers. They hold language, cultural knowledge, and a contextual understanding of education in their communities. Listening to these students, hearing them, learning from, and crucially, affording respect through responsive action has contributed to the longevity and success of the program. This is illustrated in the poetic provocation below, delivered by a student at the launch of Growing Our Own in Wadeye:

Come meet us half way

It's time for you to...learn about us

You will learn real story about me in my own environment, in my own homeland

Come with me to my place

See me as I am

I will help you understand me...

Come meet us halfway

You will learn about us for who we are

This will help you to teach our children in a real way

It will help you at school

It will help you in the classroom

It will help you become wise

It will help you build strong respect towards us and toward yourself

The way of teaching Aboriginal children will start to become clear... clear... and CLEARER if you willing to meet us halfway with an open mind and heart!

Tobias Nganbe, speech at Growing Our Own launch, Wadeye, 29th May, 2009 (quoted in Thornton, Giles, Prescott \& Rhodes, 2011, p. 236).

Nganbe's advocacy continued at an Indigenous Catholic Community Schools Leadership Meeting in 2009. The meeting coincided with the roll out of the First Four Hours of Every School Day in English Policy. He and his colleagues expressed their community's concern that the emphasis on students' performance on standardised tests at Year 3 and 5 was overshadowing first language and culture learning. They raised concerns about the appropriateness of administering mainstream tests so early in children's English language and literacy learning, and the negative impact that this has had on recognising and supporting instruction in Murrinhpatha, the children's first language (Nganbe, 2017).

Again, it was an appeal to the education system to recognise, validate and support the cultural capital held in their community. Nganbe was utilising power from his own education (Martin, 1990) to speak back to the system on behalf of his people, the school, and, in particular, his junior primary students. Poignantly too, it was also a direct signal to forthcoming lecturers to learn from and with their undergraduates.

Ladson-Billings (1992, 1995) described such interfaces as a bridge where meaningfulness between the learners' two worlds is how "culturally relevant teachers utilise students' culture as a vehicle for learning" (p. 161). Also described is pedagogy that utilises the students' culture as culturally responsive teaching 
"using cultural referents to impart knowledge, skills and attitudes" (Ladson-Billings, 1992, p. 382). The term 'culturally responsive teaching', perhaps now synonymous with cultural competence, is discussed later in this paper.

I worked to enact this approach to teaching when, in a unit that involved teaching grammar and linguistics. Even as a former secondary English teacher, I found the prescribed text turgid and demanding. I determined, as Ogbu (1987) suggested, that a "culturally relevant pedagogy must provide a way for students to maintain their cultural identity while succeeding academically" (p. 312). I started by inviting the students to describe their surroundings beginning with their local languages in the first instance: Murrinhpatha and the lingua franca, Kriol. We sought permission from elders to film at specific sites to record their multilingual decriptions of places of significance. The recordings were then parsed and analysed back in our classroom. The learning outcomes for the unit were crafted into a short film that demonstrated the students' linguistic dexterity and understanding of the required Standard Australian English grammar. As a result of this group submission, each student was awarded a Distinction at grading moderation.

While filming I saw a flock of brolgas and a lagoon blooming with crimson water lilies. I learned the local names for magpie goose and turtles, picked Billygoat plums, made string from sand palm fronds (poorly) and on the drive back home munched lily seeds picked that morning. The GOO program provides these types of opportunities for reciprocal learning. While I was learning from my Indigenous students, I was also learning more about the limits of my own knowledge and, as Nakata (2007) suggested, that was the most valuable exercise of all (p. 225).

We were transforming ourselves by learning from each other: learning both ways.

\section{Cultural competence/ intelligence/ humility}

When staff secure tenure at our university, an Indigenous cross-cultural awareness training day is mandatory, and upon completion a certificate of competence is awarded. However, a mandated Certificate in Cultural Competence does not reflect the complex and nuanced communications required for effective teaching and learning in GOO contexts.

Payi Ford (2010) wrote of her experiences as an Indigenous woman negotiating the foreign, even hostile terrain of academia, requiring the alertness of a "hunter". Our students share such trepidations. Working in community, away from the edifice of the university, the opportunities for other ways to construct knowledge are possible. Yet to do this requires skill. I become hyper-aware, looking for signs, wanting to understand peoples, country, challenges and strengths gathered from any source available to me. This need for cultural awareness and a general knowledge goes beyond my competence (Hardy \& Laszlosfly, 1995; Sermeno, 2011).

I had worked with Indigenous peoples and communities in education for many years in other states prior to coming to the NT. I had avidly read books about Australia's dark histories of death and dispossession across what was termed terra nullius and knew of intergenerational health and education inequities. But I was yet to know the particularities of these students and their community, and I tried to work with sensitivity to carefully and respectfully compare cultural differences through the lens of my own cultural experiences and make appropriate responses (Hardy \& Laszlosfly, 1995). What might be the reasons for $\mathrm{M}$ not speaking or for T not to sit next to male J? Why had S left the class and not returned? Was I too directive?

But "competence" does not do justice to our experience. 'Cultural intelligence' (Earley \& Ang, 2003) is a more accurate term in that the exercise involved a successful navigation and adaptation of different cultural experiences and settings in ways that were both natural and respectful of our respective cultures. Nevertheless, an orientation towards 'cultural intelligence' was still wanting. 


\section{Cultural humility}

Entering a community as an educator and as a guest, I felt humbled that the students shared aspects of their life stories, histories, land and cultures so generously. Beyond competence, cultural humility was what I and my colleagues, both past and present, were learning.

Cultural humility has emerged as a more suitable goal for intercultural medical education. Tervalon and Murray-Garcia (1998) defined this term, in a medical context, as "a lifelong commitment to selfevaluation and self- critique, to redressing the power imbalances in the patient-physician dynamic, and to developing mutually beneficial and non-paternalistic clinical and advocacy partnerships with communities on behalf of individuals and defined populations" (p. 117). Later, Wear (2008) contrasted competencybased approaches with the cultural humility approach to diversity. Central to her thesis, was the notion that professionalism requires the application of knowledge in unique situations for effective decisions to be made in treatment. Furthermore, (health) practitioners need to hold sensitive and appropriate dispositions, over and above knowledge and skill. These alone were considered "insufficient without a simultaneous and ongoing process of humble reflection on how one's knowledge is always partial, incomplete, and inevitably biased" (Wear, 2008, p. 626).

More simply, Reynoso-Vallejo (2009) contrasted cultural competence with humility where competence was equated with knowledge, and humility with understanding, and it was found that the latter was more effective. Foster (2009) emphasised the importance of long-term relationships in international partnerships, and especially in Indigenous Australian programs and initiatives.

To develop a stance of cultural humility, another reflexive layer needs to be added to the reflective practices of a teacher. Also, in accord with Hook, Davis, Owen, Worthington and Utsey (2013), positive relationships with Indigenous students are built upon "the ability to maintain an interpersonal stance that is other-oriented in relation to aspects of cultural identity that are most important to the client" (p. 354). Dedicated attention is required to consciously cultivate an other-orientated stance.

As lecturers we encourage our students to accept their not-knowing as both a starting point for their education journey, and as a marker at many points along the way. We encourage students to listen deeply, read carefully, reflect from multiple perspectives and speak gamely-even if the answer might not be correct. As a lecturer teaching in communities in the GOO program, I have needed to apply these same strategies to my own practice.

\section{Walking forward}

In this paper I articulate some of my experiences in prose as I have sought reflexivity in my teaching. A colleague, Dr. Al Strangeways, researched her practice in the program in Central Australia through art. Through portrait painting, narrative and analysis, and a hybrid arts-based research text (Barone \& Eisner, 1997), she engaged with various people at the school. In doing so, she began to examine the impact of shifting between the identities of teacher and artist, and how these artistic endeavours problematised her educator identity and impacted on her pedagogical practices as a teacher educator. She scrutinised her own identity—dynamic, social, multiple (Akkerman \& Meijer, 2011)—that challenged the tacit knowledge and perspectives she brought to the remote setting and her interactions with staff, children and families. She drew out three dimensions of thinking differently: looking differently, seeing differently, and being differently. These highlighted "the value of foregrounding such perceptual and ontological questioning practices in our work as teacher educators" (Strangeways, 2016, p.70). My own reflexive practices echo Strangeways' experience. Beyond the community, my way of looking seeing and being had shifted and I sought new ways to engage with my students, and the other cohort of 'aliens', international students, in particular. Below I have used the Indonesian Throughflow, the ocean current that traverses between the Pacific and Indian Oceans, as a metaphor for another subtle transformation in my journey as a teacher educator.

I am walking on the beach with a colleague and my dogs. The day is muggy and the water is warm, but we dare not enter. It holds a heady mix of creatures lurking. Will they bite, or sting or lacerate me completely? We wiggle our toes at the waters' edge and flick around in 
the safer pools that have formed away from the shoreline. There are storm clouds a-billow, but it is unlikely that it will rain. The sea is calm today yet the surface belies present currents, powerful currents whose flux is always some tousle for identity. The Arafura meets the Timor Sea; they look pretty much the same to me, on the surface, on my beach, the one I always go to. Beyond, but not so far (much closer than my family in southern Australia) surges the Indonesian Throughflow. This mighty ocean current funnels water from the Pacific Ocean through the Indonesian archipelago and around New Guinea and Timor to cool and freshen the Indian Ocean, spawn life, new life, myriad possibilities. Just over there, a massive churn and negotiation of currents, but it is smooth and sparkly on the top. There are families black and white picnicking, except the Aboriginal people are in the shade. Their voices, inaudible, roar against the tide, "This is my country!"

To the back is my university, but not before ochre sand, dripstone caves, mangroves and valiant casuarinas weathering the vagaries of the tropics. There is a rowdy band of red-tailed black cockatoos, acting like ratbags in the treetops, and circling above it all are Brahminy kites, always up there, especially in "the dry". Brahminy kites: perhaps they are also common to India, Pakistan, Nepal, Vietnam, Philippines, Singapore, China, Thailand, and Indonesia, throughout South-East Asia, where our students come from? I wonder whether any see them in the sky right now and think of home. I really do not know much about them, the international students. (Smith, 2017, pp.53-4)

\section{Conclusion}

In this paper I have tracked some of the genealogy of the Growing Our Own program including the long-standing commitment to Indigenous education by the Catholic Church up to the current partnership between the Catholic Education Office and the College of Education at CDU. Also, shown in deference to the people whose work has continued to inform the teaching and learning that occurs in the Growing Our Own program, at BIITE and in other Colleges in our university. At the risk of hubris I have given a deeply personal account of my experience in Growing Our Own, and perhaps, as Ladson-Billings (1995) stated all those years ago, "that's just good teaching," I am confident that colleagues both past and present each has their own versions of reflexive practice and transformation.

It is a long road, potholes and a corrugated track, a washed-out bridge, but no turning back. A single prop, a build-up stop. Standing tall and talking back, laughs and tears (mine and theirs). Both-ways knowledge (perhaps wisdom too). Grow for better, skills to use. Red dirt stays in your shoes. 


\section{References}

Akkerman, S. F., \& Meijer, P. C. (2011). A dialogical approach to conceptualizing teacher identity. Teaching and teacher education, 27(2), 308-319.

Barone, T., \& Eisner, E. (1997). Arts-based educational research. Complementary methods for research in education, $2,75-116$.

Devlin, B., Disbray, S., \& Devlin, N. (2017). A thematic history of bilingual education in the Northern Territory. In B. Devlin, S. Disbray \& N. Devlin (Eds.) History of bilingual education in the Northern Territory: People, programs and policies (pp. 1-10). Singapore: Springer. DOI 10.1007/978-981-10-2078-0

Earley, C. P. \& Ang, S. (2003). Cultural intelligence: Individual interactions across cultures. Stanford, CA: Stanford University Press.

Elliott, A. \& Keenan, B. (2008). Growing Our Own. Submission to DEEWR. Canberra, ACT: Australian Government.

Ford, P. (2010). Aboriginal knowledge \& country: Marri kunkimba putj putj marrideyan. Brisbane: Post Pressed.

Foster, J. (2009). Cultural humility and the importance of long-term relationships in international partnerships. Journal of Obstetric, Gynecologic, \& Neonatal Nursing, 38, 100-107.

Guenther, J., Disbray, S., \& Osborne, S. (2015). Building on 'Red Dirt' perspectives: What counts as important for remote education? The Australian Journal of Indigenous Education, 44(2), 194-206.

Guenther, J., Disbray, S., \& Osborne, S. (2016). Red dirt education: A compilation of learnings from the Remote Education Systems project. Report, https://www.nintione.com.au/?p=6490.

Guenther, J., Bat, M., \& Osborne, S. (2014). Red dirt thinking on remote educational advantage. Australian and International Journal of Rural Education, 24(1), 51.

Hardy, K. \& Laszlosfly, T. (1995). The cultural genogram: Key to training culturally competent family therapists. Journal of Marital and Family Therapy, 21(3), 227-237.

Hook, J. N., Davis, D. E., Owen, J., Worthington, E.L., Jr. \& Utsey, S. O. (2013). Cultural humility: Measuring openness to culturally diverse clients. Journal of Counselling Psychology, 60(3), 353-366.

Ladson-Billings, G. (1992). Reading between the lines and beyond the pages: A culturally relevant approach to literacy teaching. Theory Into Practice, 31(4), 312-320.

Ladson-Billings, G. (1995). But that's just good teaching! The case for culturally relevant pedagogy. Theory Into Practice, 34(3) 159-165.

Lowell, A., \& Devlin, B. (1999). Miscommunication between Aboriginal students and their non-Aboriginal teachers in a bilingual school. In Stephen May (Ed.), Indigenous community-based education (pp.137-159). Clevedon, UK: Multilingual Matters.

Martin, J. (1990). Language and control: fighting with words. In Christine Walton and William Eggington (Eds), Language: Maintenance, power and education in Australian Aboriginal contexts (pp.12-34). Darwin, NT: NTU Press.

Nakata, M. (2007) Disciplining the savages: Savaging the disciplines. Canberra, ACT: Aboriginal Studies Press.

Nganbe, T. (2011). Speech at Growing Our Own launch, Wadeye, 29th May, 2009. In S. Thornton, W. Giles, D. Prescott \& D. Rhodes (2011). Exploring the mathematical confidence of Indigenous preservice teachers in a remote teacher education program, Mathematics Education Research Journal, 23, pp. 235-252. 
Nganbe T.N. (2017). Defending our program at Wadeye. In: B. Devlin, S., Disbray, N. Devlin (Eds). History of bilingual education in the Northern Territory: People, programs and policies (pp. 179184). Springer, Singapore. DOI 10.1007/978-981-10-2078-0

Nicholls, C. (2005). Death by a thousand cuts: Indigenous language bilingual education programmes in the Northern Territory of Australia, 1972-1998. International Journal of Bilingual Education and Bilingualism, 8(2-3), 160-177.

Ober, R. (2004). Reflections on both-ways at Batchelor Institute. Ngoonjook: a journal of Australian Indigenous issues, 8-9.

Ober, R. \& Bat, M. (2007). Paper 1: Both-ways: the philosophy. Ngoonjook: a journal of Australian Indigenous issues, 31, pp.64-86.

Ogbu, J. (1987). Variability in minority school performance: a problem in search of an explanation. Anthropology and Education Quarterly, 18(4), 312-334.

O'Loughlin, J. P. (1986). The history of the Catholic Church in Northern Territory. Occasional Papers No. 2, Library Services of the Northern Territory, Darwin. Retrieved from http://www.territorystories. nt.gov.au/jspui/bitstream/10070/134408/1/occpaper2.pdf

Reedy, A., \& Gulwa, H.W. (2016). Online learning and teacher education: The experiences of Indigenous teacher education students. Learning Communities: International Journal of Learning in Social Contexts [Special Issue: New Connections in Education Research], 20, 40-51. DOI: http://doi. org/10.18793/LCJ2016.20.04.

Reynoso-Vallejo, H. (2009). Support group for Latino caregivers of dementia elders: Cultural humility and cultural competence. Ageing International, 34(1-2), 67-78.

Sermeno, S. E. (2011). Building a case for cultural sensitivity through personal storytelling and interpersonal dialogue in international education. International Schools Journal, 30(2), 10-17.

Slee, J. \& Keenan, B. (2009, November). Culturally responsive assessment strategies to inform a pilot program for Indigenous teacher education in remote communities of the Northern Territory of Australia. Paper presented to a Symposium on Tertiary Assessment and Higher Education Student Outcomes, Victoria University, NZ.

Slee, J. (2010). A systematic approach to culturally responsive assessment practices and evaluation, Higher Education Quarterly, 64(3), 246-260.

Smith, S. E., (2017). Riding the throughflow: disrupting colonial discourse through cultural humility. In A. Lian, P. Kell, P.Black, \& K.Yew Lie (Eds.), Challenges in global learning: dealing with education issues from an international perspective (pp. 52-67). Newcastle upon Tyne, UK: Cambridge Scholars Publishing.

Strangeways, A. (2016). The people of the school: Problematising remote teacher educator identity, reflexivity and place. Learning Communities: International Journal of Learning in Social Contexts [Special Issue: New Connections in Education Research], 20, 70-81. DOI: http://doi.org/10.18793/ LCJ2016.20.07.

Tervalon, M., \& Murray-Garcia, J. (1998). Cultural humility versus cultural competence: A critical distinction in defining physician training outcomes in multicultural education. Journal of Health Care for the Poor and Underserved, 9(2), 117-125.

Wear, D. (2008). On outcomes and humility. Academic Medicine, 83(7), 625-626. 